\title{
LA 'EXPLOSIÓN DE LA COSIFICACIÓN'. APUNTES PARA UNA TEORÍA MATERIALISTA DE LA EMANCIPACIÓN SOCIAL
}

\author{
The 'Explosion of Reification'. Notes for a Materialist Theory of Social \\ Emancipation
}

\author{
Chaxiraxi Escuela Cruz
}

Universidad de La Laguna

cescuela@ull.es

\begin{abstract}
Resumen:
El desarrollo de una teoría crítica de lo social de inspiración marxista y orientada a la denuncia de las formas de control que pesan sobre el individuo puede ser interpretado como el imperativo que guió los esfuerzos teóricos de los filósofos frankfurtianos. Este trabajo presenta una lectura de los momentos de especificidad de la propuesta de recuperación de la teoría materialista de lo social, en especial atendiendo a la teoría de la cosificación tal como aparece en Adorno, Horkheimer y Lukács.
\end{abstract}

Palabras clave:

Cosificación, materialismo, Teoría Crítica, emancipación, dominación

\begin{abstract}
:
The development of a critical theory of the social that focuses on denouncing the forms of control and the social domination guided the theoretical efforts of the Frankfurt philosophers. The main goal of this article is to present the specific moments of the recovery proposal of the materialist theory of the social, especially the theory of reification as it appears in Adorno, Horkheimer and Lukács.
\end{abstract}

Keywords:

Reification, Materialism, Critical Theory, Emancipation, Domination

Recibido: 26/08/2019

Aceptado: 11/11/2019 
La Teoría Crítica surgió como uno de los más interesantes esfuerzos de los emprendidos en el periodo entreguerras por asumir y enriquecer la filosofía de Marx, a partir del intento de analizar las sociedades capitalistas posliberales a la luz de los fenómenos transformadores de carácter social, político, cultural y económico de la segunda mitad de la década de los veinte. Herederos de los principios teóricos y metodológicos del pensamiento marxista, sus trabajos mostraron las consecuencias que dictaba una compleja reorganización de la sociedad burguesa tardocapitalista marcada por la incertidumbre ante la confianza en el mantenimiento de los postulados liberales que apuntaban a la emancipación y, también, por el peligro que representa el endurecimiento progresivo de las formas de coerción social. En medio de una novedosa aceleración de los procesos de transformación de las formas de vida tradicionales, el principal desafío al que tuvieron que hacer frente fuese el de mantener las aspiraciones de libertad y autonomía en un momento en el que ya no resultaban evidentes por sí mismas.

"Derribar las relaciones en las que el hombre es un ser humillado, esclavizado, abandonado y despreciado" (Marx 1976: 385) continuaba siendo el imperativo moral que guiaba los análisis de los teóricos frankfurtianos ${ }^{1}$. Pero las formas de integración social que se evidencian en la extensión de una sociedad tecnificada y masificada daban por incumplido el pronóstico de Marx sobre la desarticulación automática de las relaciones dominantes de producción. Los procesos transformadores que aparecen tras la desintegración del mundo burgués abren las puertas a un modelo social que genera formas totalitarias de dominio distintas a las conocidas y que se extienden sobre los individuos, de manera irreversible, integrándolos una estructura funcional y antagonista. Sin embargo, esto no sólo exige abordar la situación crítica que amenaza a las aspiraciones sociales de emancipación tras la extinción del optimismo que albergaba la modernidad con respecto a las posibilidades de libertad del individuo.

La crisis del mundo burgués también encontró expresión en el fracaso de los proyectos socialistas, que pronto mostraron su insuficiencia. Incluso las filosofías que aparecieron como respuesta a este derrumbe y que trataron de recuperar la teoría marxista, mostraron su incapacidad para comprender las causas de la crisis de la modernidad. El proyecto marxista se vio afectado por una lectura incompleta que abandonaba su comprensión originaria como teoría crítica para la superación del dominio, y que lo reducía a un conjunto de respuestas estandarizadas sobre la historia o la sociedad, una concepción cerrada del mundo y un sistema dogmático de creencias. Como se puso de manifiesto en las discusiones que los miembros del Instituto llevaron a cabo durante los años treinta acerca de la forma adecuada de comprender el método de análisis marxista, solo una teoría materialista de la historia y de lo social podía ser capaz de dar una respuesta a la experiencia de la revolución

\footnotetext{
${ }^{1}$ Una reconstrucción de algunas claves presentes en el proyecto moral de la Teoría Crítica se encuentra en: Escuela Cruz, C. (2018) "Moral y capital. Repensando el desafío ético de la Teoría Crítica", en: Escuela Cruz, C. y Álvarez, D. (coords.), Repensar la filosofía. La Laguna: Servicio de Publicaciones de la Universidad de La Laguna, pp. 69-89.
} 
frustrada y, todavía más importante, de retomar los impulsos liberadores de la tradición ilustrada,

aquella que en Europa ha tenido su repercusión crítica o ha sido completamente aniquilada. Con eso se ha pensado, sobre todo, en la Ilustración francesa e inglesa, y en el idealismo clásico alemán hasta Marx. Pero para conservar vivos los elementos de esa tradición no basta su simple repetición y su mecánica aplicación en el presente, sino el perfeccionamiento positivo por medio de la utilización de los conocimientos más modernos de todos los ámbitos del saber (Horkheimer 1985a: 143-144)

Se trataba, pues, de replantear el método y el alcance de la tradición de pensamiento materialista para esclarecer de qué manera los cambios acontecidos en la estructura económica, en lugar de desembocar en la autodisolución del sistema, habían conducido a ejercer una mayor presión sobre los aspectos públicos y privados de la vida. Esto requería dejar de tomar el marxismo como un catecismo teórico incuestionable y hacerlo, en su lugar, como una infraestructura filosófica que exige una reactualización de sus temas y presupuestos para hacerlo relevante en medio de las nuevas experiencias epocales. "Mantener el impulso radical del marxismo y de la ilustración al completo" (Horkheimer 1985b: 598) rehabilitar la fuerza de sus análisis, significa la formulación de un contenido concreto, esto es, una teoría materialista de la sociedad que comprenda el origen de la miseria y del sufrimiento humano en la organización económica burguesa. Pero la teoría crítica de Adorno y Horkheimer no sólo planteaba la crítica a la economía política como un componente esencial del funcionamiento de la sociedad capitalista. El aumento de la productividad técnica y económica había establecido las condiciones más adecuadas para el avance social. Pero no solo no habían ayudado a superar la carencia y la desigualdad, sino que también habían colaborado con el incremento del poder y del control, y la consecuente precariedad. No basta, por tanto, con sacar a la luz la «ley económica que atraviesa el mundo», pues la irracionalidad de la tardía sociedad burguesa se resistía a ser comprendida de manera inmediata. La crítica a la economía política de Marx se amplía entonces al cuestionamiento de un proceso totalitario de reproducción de la vida que obstaculiza la pretendida emancipación de los individuos. Había que buscar la causa del sufrimiento en los procesos de reproducción social que imponen su forma de abstracción y de nivelación sobre los individuos y sus relaciones ${ }^{2}$. Esto explica que completaran la crítica a la economía política con los resultados de la crítica cultural o de la psicología social, pues en sus aportaciones se reflejaban las consecuencias de un modelo de reproducción social basado en la administración y la integración total.

${ }^{2}$ Para un análisis reciente del papel representado por el "sufrimiento" en la obra Adorno, véase el volumen colectivo: Stöhr, R. et al. (2019) "Leiden beredt werden lassen". Theodor W. Adornos Reflexionen des beschädigten Lebens. Wiesbaden: Springer Fachmedien. 
El año en el que se ponen en marcha los procesos que conducirían a la formación del Institut en Frankfurt tiene lugar la Erste Marxistische Arbeitswoche, unas jornadas de encuentro entre las distintas corrientes marxistas de la época en un esfuerzo por enfrentarse a los problemas generados por la crisis del marxismo tras la experiencia de la Primera Guerra Mundial y el fracaso de la democracia social de la Segunda Internacional. El ámbito de referencia teórica de estas reuniones fue el llamado marxismo crítico occidental y sus esfuerzos emprendidos por rehabilitar la dialéctica hegeliana como tema dominante. Fundamental para ello fue la publicación de sus dos obras más importantes: Marxismo y filosofía de Karl Korsch y, sobre todo, Historia y conciencia de clase de György Lukács. La aparición de estos trabajos significó una ruptura con la interpretación del marxismo cientificista, así como la apertura de una posibilidad de interpretación filosófica del materialismo histórico que, a diferencia de la economicista, acentuara su olvidado nervio transformador y convirtiera el camino hacia la emancipación de la humanidad en el resultado de la acción revolucionaria.

Historia y conciencia de clase reunió diversos ensayos políticos escritos por Lukács entre los años 1919 y 1922. Como el propio autor reconoció, se trataba de la conclusión y la síntesis de un periodo de desarrollo personal e intelectual a partir de los últimos años de la guerra. Si bien su acercamiento a Marx tuvo lugar durante sus años de formación, lo cierto es que son las consecuencias de la Primera Guerra Mundial y de la Revolución Rusa las que determinaron las bases de una transformación profunda en el obrar político y filosófico del autor que terminarían por consolidar Historia y conciencia de clase como una de las obras de referencia del marxismo en el siglo $X^{3}$. El propósito de Lukács era reflexionar sobre el método del marxismo. Defendía la posibilidad de desarrollar una «ortodoxia marxista», es decir, una radicalización de la dialéctica revolucionaria como método marxista por antonomasia a partir del convencimiento de que "con el marxismo dialéctico se había encontrado el método de investigación justo y de que este método solo podía ser desarrollado y perfeccionado, ya que todo intento de superarlo o mejorarlo terminaba por hacerlo superficial, trivial y ecléctico" (Lukács 1968: 171). Lukács quería recuperar los fundamentos teóricos de la investigación marxista como un método de conocimiento y de transformación, para enfrentarlos a los equívocos en los que se había enredado la interpretación de Marx Ilevada a cabo por los autores de la Segunda Internacional. La interpretación mecanicista del marxismo llevada a cabo por autores como Bernstein, Bauer o Adler, se apoyaba en el interés por «descontaminar» el análisis materialista de la historia de los presupuestos de interés revolucionario. El resultado fue un deterioro de los principios transformadores de la teoría que olvidaban el momento dialéctico como nervio vital del método marxista. Por ello, Lukács consideraba urgente la tarea de "liberar sus categorías de todas las deformaciones burguesas tardías a fin de hacerlas adecuadas al gran salto revolucionario en el

\footnotetext{
${ }^{3}$ La novedad que representó Historia y consciencia de clase según Jay consistió en "su intrincado entrelazamiento de cuestiones teóricas con cuestiones prácticas, su embriagadora mezcla de idealismo alemán, materialismo histórico y una teoría sociológica avanzada, que culminó en una defensa a ultranza de las virtudes organizativas del partido de vanguardia" (Jay, 2018: 196).
} 
presente" (Lukács 1986: 20), lo que exigía una actualización del núcleo histórico y social del pensamiento de Marx a través de la activación de la dialéctica hegeliana en la unión de sus momentos teóricos y prácticos.

Continuaba entonces con el que había sido el tema central de algunas de sus obras anteriores como El alma y sus formas (1911) o Teoría de la novela (1915), y que consideraba el principal problema al que debía hacer frente la filosofía: la desintegración de las formas tradicionales de pensamiento y de acción que daban lugar a las contradicciones del mundo burgués. El diagnóstico de la alienación total del mundo histórico le condujo a analizar la idea de cosificación como categoría universal en la teoría de lo social. Presentaba la teoría marxista del fetichismo de la mercancía como un problema específico del capitalismo moderno, puesto que en él, por primera vez, la estructura de la mercancía se convierte en la forma universal dominante en los procesos de racionalización social ${ }^{4}$. Estos procesos se traducen en la enajenación de los individuos con respecto a una realidad social que, pese a ser producto suyo, se presenta como «segunda naturaleza» y sobre la que pierden control. La cosificación aparece entonces como un proceso dúplice. Por un lado, genera una forma determinada de objetividad, un mundo de cosas y de relaciones entre ellas determinado por las leyes económicas. Por otro, también le corresponde una forma concreta de subjetividad - la conciencia cosificada - de ahí que a la descomposición del objeto en la producción le siga el desgarramiento y la atomización del sujeto (cfr. Festl 2019: 59).

Lukács entendía esta atomización como el reflejo del sometimiento de todas las manifestaciones vitales de la sociedad a las leyes naturales de la producción capitalista. En esta identidad entre las formas de socialización y las de pensamiento, la cosificación se muestra como «fenómeno ideológico» y, también, como sinónimo de la fragmentación que refleja una totalidad perdida. Por eso, veía el concepto de «totalidad», es decir, el dominio universal del todo sobre las partes, como el elemento de continuidad entre Hegel y Marx, y precisamente por esta razón, también el lugar desde el que creía posible recuperar el nervio revolucionario de la teoría materialista ${ }^{5}$. Exigía entender el desarrollo histórico como el despliegue dialéctico del espíritu desde la inconsciencia hasta la plena conciencia de sí mismo. La totalidad de la sociedad no es otra cosa que el producto histórico de la praxis humana, que había sido erróneamente olvidado bajo las condiciones de vida capitalista. La escisión de la sociedad en elementos aislados que se caracterizan por su aparente irresistibilidad refleja el sentimiento moderno de la pérdida de la totalidad. Por eso, sólo se logra comprender el funcionamiento del sistema social capitalista si se tiene en cuenta que no es posible explicar las determinaciones inmediatas de la vida social de manera

\footnotetext{
4 Sobre análisis de la categoría de fetichismo de la mercancía en Marx, véase: Ramas San Miguel, 2018.

5 También Postone insiste en atribuir a Lukács una apropiación materialista de Hegel, en contraste con la crítica histórica realizada por Marx. "La posición de Marx difiere fundamentalmente de la de Lukács, ya que este último ve la totalidad afirmativamente e identifica el sujeto-objeto idéntico de Hegel con el proletariado" (Postone 1993: 74).
} 
aislada, sino como momentos de un desarrollo histórico total. Es aquí donde mejor se expresa el deseo luckácsiano de buscar el Marx gran dialéctico de la revolución, frente al Marx científico propio de la socialdemocracia (Sacristán 1983: 238). Con ello Lukács se enfrentaba a la teoría del reflejo, pues la conciencia deja de ser comprendida como un mero reflejo del ente económico autonomizado, para mostrarse como una parte de la totalidad que la determina constantemente.

Por eso, no se trataba solo de un problema teórico, sino fundamentalmente práctico y transformador. Culpabilizaba a los teóricos de la Segunda Internacional de haber sacrificado el principio de la praxis por inscribirla en una teoría del reflejo, y recordaba su sentido dialéctico para reivindicar la capacidad del sujeto de tomar conciencia de la situación histórica que le rodea y transformarla. La dialéctica materialista es comprendida entonces como una dialéctica revolucionaria. Por eso, la identidad entre sujeto y objeto, entre teoría y praxis, se concreta en la figura del proletariado como sujeto de la revolución. Frente a las interpretaciones cientificistas y objetivistas, Lukács comprendía el método marxista como una forma de conocimiento de la realidad que sólo se pone en marcha desde el punto de vista de la lucha de la clase proletaria. "La acción y la praxis implican por esencia una penetración, una transformación de la realidad", escribe, "pero la realidad sólo puede ser captada como totalidad, pues sólo un sujeto que sea a su vez una totalidad puede hacer esa penetración" (Lukács 1986: 121-122). Es a partir del punto de vista de clase del proletariado, en tanto "sujeto capaz de transformar lo social" (Westerman 2019: 153) y de su imperiosa necesidad de comprender su propia situación, desde donde la sociedad se hace visible como totalidad. En ella coincide el conocimiento de sí mismo con el de las fuerzas reales que determinan la totalidad del proceso histórico:

El método marxista, la dialéctica materialista como conocimiento de la realidad, no se consigue más que desde el punto de vista de la lucha del proletariado. El abandono de ese punto de vista aparta del materialismo histórico, del mismo modo que su consecución lleva directamente a la lucha del proletariado (Lukács 1986: 35).

Cifraba la posibilidad real de una superación de la cosificación en la conciencia de clase del proletariado y la interpretaba como el desarrollo de una forma de conciencia distinta, la conciencia de clase. En ella no se «refleja» el curso de un proceso social que se encuentra en marcha, sino que tiene como cometido la transformación de la situación histórica en la que se encuentra integrada. Por eso, sólo es posible hablar de un conocimiento completo de la realidad social con la aparición de la conciencia del proletariado. "Lo que ha surgido con el materialismo histórico", apunta, "es a la vez la doctrina de las condiciones de la liberación del proletariado y la doctrina de la realidad del proceso total del desarrollo histórico" (Lukács 1986: 193). En ella coincide el conocimiento de sí mismo como sujeto y el de la totalidad social como objeto, por lo que solo asumiendo esta coincidencia será posible activar el núcleo transformador del materialismo marxiano. 


\title{
3.
}

Adorno y Horkheimer valoraron Historia y conciencia de clase como uno de los más importantes intentos de rehabilitación del momento crítico del materialismo al hacer valer el análisis del fetichismo de la mercancía y de la cosificación - que había sido olvidado por la crítica marxista - como espacio central para la elaboración de una filosofía de la historia concreta. Un mérito aún mayor si se tiene en cuenta que en el momento en el que Lukács escribe su obra aún no habían sido publicados los Manuscritos económicos-filosóficos de 1844, en los que Marx distinguía entre objetivación, como forma natural y eterna del proceso de trabajo, y cosificación o modo de ser propio del trabajo en la sociedad capitalista. En el caso de Adorno, son numerosos los textos en los que reconoce la influencia que tuvo la lectura de los textos del filósofo húngaro en su temprana aproximación a Marx. Ya en su primera conferencia "La idea de historia natural» atribuyó a Teoría de la novela el valor de haber elaborado una filosofía de la historia objetiva con la que denunciaba la apariencia pseudonatural en la que deviene la realidad cuando se presenta como ahistórica. Allí puso de relieve la idea de «mundo de la convención» que Lukács usaba para referirse al mundo social e histórico producto de la actividad humana ante el cual, sin embargo, el individuo se sentía extraño. En ella encontró un apoyo fundamental para la elaboración de la pregunta sobre la que articularía su pensamiento materialista en torno a la posibilidad de comprender un mundo social desintegrado y vacío de sentido, paralizado en naturaleza:

\begin{abstract}
Este hecho del mundo de la convención tal como es producido históricamente, el de las cosas que se nos han vuelto ajenas, que no podemos descifrar pero con las que nos encontramos como enigmas, es el punto departida de la problemática que hoy expongo aquí. El problema de la historia natural se presenta como la pregunta acerca de cómo es posible interpretar y conocer este mundo enajenado, cosificado y muerto (Adorno 1973: 356).
\end{abstract}

Sin embargo, pese a estos momentos de continuidad, Adorno nunca compartió sin reservas la interpretación del materialismo de Lukács, pues la consideró un esfuerzo frustrado por superar la parálisis de la filosofía marxista. Su posición crítica tiene como punto de partida la solución totalizadora que se deduce de su filosofía de la historia cuando conecta la falta de sentido que da lugar a la desintegración social con la pérdida del referente de la totalidad. Lukács había introducido la noción de totalidad - "portadora del principio revolucionario de la ciencia" (Lukács 1986: 39) - como elemento central en su lectura no positivista del marxismo. Sólo a través de la contemplación dialéctica de la totalidad veía posible una comprensión adecuada del proceso histórico como unidad y, en consecuencia, también una transformación de las relaciones sociales cosificadas:

Lo que diferencia decisivamente al marxismo de la ciencia burguesa no es la tesis del predominio de los motivos económicos en la explicación de la historia, sino le punto de vista de la totalidad. La categoría de totalidad, el dominio omnilateral y determinante del todo sobre las pares, es la esencia del método que Marx tomó de Hegel (Lukács 1986: 22). 
Adorno cree que esta toma de partido por la totalidad convierte la dialéctica histórica en una identidad paralizada entre sujeto y objeto, lo que supone una recaída en viejas posiciones idealistas que precisamente Lukács quería evitar. La crisis del sistema idealista es comprendida por Adorno como la crisis de la pretensión de totalidad y de sentido, una vez constatada la disonancia entre lo real y lo racional. Abandonar la ilusión de apresar la totalidad de lo real con la fuerza del pensamiento significa asumir la quiebra de la forma tradicional de fundamentación teórica. Esto significa el esfuerzo por presentar un concepto de dialéctica distinta a la hegeliana, que sitúe el acento en la existencia de un proceso de mediación real no totalitaria entre sujeto y objeto:

\begin{abstract}
Cuando se expone una dialéctica materialista como un principio absoluto y metafísico surge una gran dificultad, pues la dialéctica es moverse entre opuestos. Sin el momento de la reflexión, es decir, sin el momento de que una cosa se haga su otreidad gracias a la conciencia, no es pensable todo esto. Pero como solamente en una conciencia puede darse el reflejo en su otreidad, no se puede separar de la dialéctica el momento de la subjetividad o de la reflexión. Pero, tan pronto como esto sucede, se da ya, filosóficamente, en ese momento el fundamento para el paso a una religión de Estado que hemos podido observar con terror en la decadencia de la teoría dialéctica (Adorno 1974: 159-160).
\end{abstract}

La dialéctica materialista asume la consciencia de la mediación entre sujeto y objeto, y denuncia como forma de mistificación la identificación entre razón e historia. Por eso, la filosofía materialista de Adorno se presenta como una abierta y no reducida, sensible a la no-identidad de lo particular con lo general. Apelar como Lukács a la totalidad sin tener en cuenta el momento de mediación significa olvidar las dimensiones reales de la cosificación, pues "únicamente una conciencia cosificada se figura o hace creer a los otros que posee fotografías de la objetividad" (Adorno 1970: 205). Por eso, si la mercancía representaba el germen de la sociedad capitalista en Historia y conciencia de clase, el análisis de la estructura económica en Adorno tiene como objeto el completo proceso totalitario de reproducción social que obstaculiza la pretendida emancipación de los individuos.

\title{
4.
}

El análisis de la mercancía y del fenómeno de la cosificación es el eje central de Historia y conciencia de clase, pues "el método dialéctico, al mismo tiempo que desgarra el velo de eternidad de las categorías, debe también desgarrar su velo de coseidad para abrir el camino al conocimiento de la realidad" (Lukács 1968: 187). La estructura de la mercancía adopta una forma universal en medio de las manifestaciones de la vida social, pues no sólo presenta la realidad como un conjunto de cosas acabadas cuyas leyes de funcionamiento resultan incomprensibles a los sujetos, sino que su propia actividad se torna abstracta y alejada de su control. También Adorno asume la problemática de la teoría marxiana de la mercancía, pues la considera "una pieza fundamental de la herencia de la filosofía clásica alemana" (Adorno 1970: 190), de ahí que reconozca el valor del análisis de Lukács sobre el 
concepto de cosificación frente al mecanicismo de versiones anteriores del marxismo. Ya en su escrito de habilitación universitaria sobre Kierkegaard, Adorno había prestado atención a la representación de la mercancía en Marx como "quintaesencia de la conexión entera de todos los fenómenos de la sociedad capitalista que guarda la memoria de la totalidad" (Adorno 1962: 151). Su desciframiento permite explicar lo universal de la economía capitalista y, con ello, también la raíz ideológica de la sociedad. Asumir el ideal de humanidad de Marx como la representación de un estado de reconciliación entre los intereses particulares de los individuos y los generales de la sociedad significa apuntar a la "explosión de la cosificación" (Adorno 1984: 810), como la abolición de los mecanismos que se derivan de la estructura deformada de la sociedad capitalista. Como apuntaba, "se trataría de alcanzar un estado en el que se eliminara el dominio ciego que ejercen las condiciones materiales sobre los hombres y en el que la pregunta por la libertad no tuviera sentido" (Adorno 1974: 198).

Como se ha señalado, Lukács no conocía los Manuscritos de 1844, hecho que influyó decisivamente en su comprensión del concepto de cosificación, como lamentaría en su conocida nota autocrítica de años después ${ }^{6}$. En ellos, el capitalismo se presentaba no sólo desde una perspectiva económica o política, sino en relación con una catástrofe de la propia esencia humana. Para Marx, la superación del momento de cosificación dependía del establecimiento de un orden de producción distinto, algo que sólo veía posible en la propia acción del individuo, es decir, en la superación del trabajo en sí mismo.

Adorno, por el contrario, sí conocía los Manuscritos, ya que a finales de los años veinte el Instituto había recibido algunas copias de manos de David Riazánov, entonces director del Instituto Marx-Engels y editor de la Marx-Engels historischkritische Gesamtausgabe. Su conocimiento de estos textos inéditos le permitió acusar a Lukács de hacer un tratamiento demasiado limitado de la cosificación, por no haber tenido en cuenta que la apariencia de «objetividad fantasmal» que atribuye a las leyes del sistema capitalista no puede olvidar la tarea de desvelar las leyes objetivas que se ocultan en las relaciones de producción. Por eso, las consideraciones de Adorno en torno al principio de intercambio y el carácter fetichista de la mercancía no se limitaron al ámbito de la crítica a la economía política, sino que fueron interpretadas como la causa y el fundamento del mal social. Si para el filósofo húngaro la identificación entre la forma de la mercancía y su carácter fetichista conducía a remitir el fenómeno de la cosificación únicamente a un hecho de conciencia, Adorno ve en la racionalidad del intercambio de mercancías el modelo social del principio de identidad que reduce el mundo a lo idéntico:

\footnotetext{
${ }^{6}$ Lukács tiene la oportunidad de leer el texto en 1930, cuando trabajaba como colaborador del Instituto Marx-Engels de Moscú: "Recuerdo todavía hoy la impresión profunda que me produjeron las palabras de Marx sobre la objetividad como propiedad material primaria de todas las cosas y de todas las relaciones. A ella se unía (...) la comprensión del hecho de que la objetividad es un modo natural de dominio humano del mundo, mientras que la enajenación es un tipo particular de objetivación que se realiza en determinadas circunstancias sociales. Con esto se derrumban definitivamente los fundamentos teóricos de lo que representaba el carácter particular de Historia y conciencia de clase. Este libro me llegó a ser completamente extraño" (Lukács 1986: 43).
} 
La abstracción del principio de intercambio se relaciona con el dominio de lo general sobre lo particular, de la sociedad sobre sus miembros. Por tanto, no es neutral. En la reducción de los individuos a agentes y portadores del intercambio de mercancías se esconde el dominio del hombre sobre el hombre. Eso permanece como algo cierto, pese a todas las dificultades a las que se enfrentan algunas de las categorías de la Crítica a la economía política (Adorno 1972: 13).

Adorno se refiere a la tendencia abstracta hacia la generalidad propia que conduce al fortalecimiento de formas totalitarias en las que los sujetos pierden su individualidad al ser sometidos a la totalidad social. La abstracción del principio de intercambio se relaciona con el dominio de lo general sobre lo particular, de la sociedad sobre sus miembros, cuando nivela y elimina las cualidades singulares y los reduce a un denominador común. Con otras palabras, el principio de intercambio "reduce el mundo entero a algo idéntico, a la totalidad" (Adorno, 1970: 149). Se trata, pues, de un equivalente que actúa de manera abstracta y universal, pero que tiene consecuencias reales, pues su lógica no sólo determina los procesos económicos o los objetos del mercado, sino el conjunto de la vida social. Se introduce en el conjunto de la realidad social bajo la forma del dominio de lo universal (la sociedad) sobre lo individual (sus miembros). Este es el predominio de la totalidad social antagónica sobre sus partes. Aquí ve Adorno la violencia con la que se impone la lógica del capital al liquidar las formas individuales de realización de la vida.

"La conversión del mundo y de la vida al completo en un sistema de administración y de gestión dispuesto desde arriba" (Horkheimer y Adorno, 1989: 134) conduce a una tendencia social desintegradora en la que no sólo los objetos del mercado se someten a los procesos de nivelación y clasificación, sino que también los ámbitos públicos y privados de la vida acaban reducidos a funciones en el interior de la maquinaria social $^{7}$. Categorías asociadas a los productos del mercado (como la estandarización, la homogenización o la intercambiabilidad) acaban por trasladarse a las relaciones personales. Adorno se acerca a la cosificación desde una perspectiva social y epistemológica, que no la entiende únicamente como un hecho de conciencia, sino como productor mismo de conciencia. "Si tuviera que expresar en una única frase el secreto de la sociedad actual", apunta, "diría que hoy el aparato de reproducción de la vida coincide irremediablemente con el de su dominio" (Adorno 2003: 9). El aparato que permite la reproducción de la vida es el mismo que la obstaculiza, pues el individuo desaparece integrado y desintegrado en una estructura funcional $y$ antagonista que depotencia y degrada su vida. Por eso, dirige su crítica a la abstracción que tiene lugar en la cosificación y que desarrolla una forma específica de subjetividad. En ella ve, una vez más, el carácter antinómico del sistema capitalista. Por un lado, presenta una pluralidad basada en formas de vida cada vez más individualizadas, insistiendo en la conquista de logros individuales y en el refuerzo de un ejercicio de autorresponsabilidad sobre el propio destino social y económico. Pero,

\footnotetext{
${ }^{7}$ Para Zamora, "la forma de reproducción del capital es un mundo invertido en el sentido de que, a través de las acciones que aseguran su reproducción y en ellas, se independiza respecto de los individuos que los ejercen, y desarrolla una dinámica propia conforme a leyes que funcionan, por así decirlo, a sus espaldas" (Zamora 2011: 80).
} 
de otro lado, socava todas las condiciones estructurales que hacen posible esta autodeterminación. Solo lo logramos cuando nos sometemos al mecanismo de reproducción social que nos anula y nos convierte en un engranaje más. Esta pseudoindividualización o culto a la personalidad esconde, en definitiva, la liquidación del individuo real. Cuánto más profunda es la forma en la que el individuo es sometido a las exigencias de la totalidad antagónica, mayor es también la fuerza con la que se entroniza al sujeto.

Por eso, cosificación y subjetividad no son antagónicos. No es lo opuesto a la presencia del sujeto, sino una función de este, pues "cuánta más cosificación haya, más subjetivación se dará en la filosofía" (Adorno, 1995: 174). Tanto el sujeto como el objeto acaban cosificados cuando se olvida el carácter mediado de ambos. El olvido de la mediación - del ser-objeto y material del sujeto y de la necesaria intervención subjetiva en el objeto - será interpretado por Adorno como una forma de cosificación. La cosificación es el olvido de la génesis como resultado de la hipóstasis idealista del sujeto, por lo que la tarea de una filosofía materialista negativa será presentar este olvido como ideológico ${ }^{8}$. Des-cosificar, por tanto, ya no tendrá el sentido lukácsiano de ligazón inmediata con la totalidad, sino más bien el de un ejercicio de memoria contra la presentación de la identidad como absoluta. Este tratamiento dialéctico de la cosificación y del intercambio que pone de relieve la presencia de una forma silenciosa de dominio de lo individual bajo el control y la integración social, tendrá también consecuencias en la forma de entender la figura del sujeto revolucionario de la historia.

\title{
5.
}

Lukács veía en el proletariado el sujeto capaz de llevar a cabo una organización de la totalidad de la sociedad en conformidad con sus intereses:

\begin{abstract}
La unidad de la teoría y la práctica no es sino la otra cara de la situación histórica-social del proletariado, el hecho que desde su punto de vista coinciden el autoconocimiento y el conocimiento de la totalidad, el hecho de que es a la vez sujeto y objeto por su propio conocimiento (Lukács 1986: 193).
\end{abstract}

Sin embargo, mientras que Lukács cree posible alcanzar un camino directo hacia la formación de la conciencia de la clase trabajadora, para la Teoría Crítica esta posibilidad permanece cerrada. Desde los años veinte se evidencia en el círculo frankfurtiano la desconfianza ante el movimiento obrero como depositario de las posibilidades de una transformación social. Las pocas esperanzas que albergaban en el desarrollo de un socialismo humanista se desvanecieron por completo tras los acontecimientos sociales y políticos que había generado en Europa el desarrollo de las formas de totalitarismo. La agudización del antagonismo social y de la desigualdad de clases habían facilitado al capital presentarse como una instancia anónima, es decir

\footnotetext{
${ }^{8}$ Reichelt pone de manifiesto la consideración adorniana de una abstracción real que tiene lugar como "proceso de constitución, al cual pertenece esencialmente el hecho de que la génesis se ha desvanecido en el resultado" (Reichelt, 2013: 24).
} 
como la expresión inevitable del conjunto de los intereses de la sociedad, lo que conducía a un debilitamiento de la capacidad para la autorreflexión crítica de la propia situación de los individuos.

La atrofia de la subjetividad y la introducción de sutiles mecanismos de control habían conducido al debilitamiento de cualquier posibilidad coordinada o grupal de transformación. Por eso, no podía comprenderse el materialismo como un fundamento teórico para la legitimación de las luchas del proletariado, ni tampoco ellas se debían subordinar a las posiciones teóricas del materialismo, pues la situación que diagnosticaba en la clase trabajadora "convertía en superficial la fundamentación y justificación metafísica de la revolución" (Horkheimer, 1987: 264). La praxis revolucionaria defendida por Lukács cuando confiaba en la conciencia de clase como el motor de la transformación social es vista ahora como una praxis fracasada. Cualquier esperanza en una teoría revolucionaria que sirviera de base para el establecimiento de una organización social justa, se atisba desde el nuevo horizonte histórico como ingenua.

Sin embargo, la denuncia de Adorno no se dirige a la capacidad de la acción transformadora en sí misma, sino a una comprensión de la praxis entumecida que ha renunciado a sus vínculos con la teoría y ha acabado convertida en un accionismo irracional. La auténtica praxis que pudiera corresponder a la idea de una emancipación se encontraba aún obstruida, por lo que era urgente reflexionar sobre los motivos y las causas de esta obstrucción. Esto significa que la teoría y la praxis deben reflexionar sobre sus posibilidades de realización, para evitar ser estériles o acabar convertidas en herramientas al servicio de la barbarie, y en su lugar enfrentar "la emergencia de impulsos de oposición frente a la dominación ciega, de libertad para fines elegidos racionalmente, de asco frente al mundo como mentira y representación, y de recuerdo ante la posibilidad del cambio" (Adorno 1972: 368). Una teoría que no muestre relación con la praxis acaba condenada a ser una "pieza de conocimiento muerto», de la misma forma que una praxis que sólo quiera liberarse de los grilletes de la teoría se reduce a pseudoactividad. Por eso, Adorno encuentra el espacio de resistencia dentro de la sociedad administrada en la capacidad del sujeto para experimentar lo particular y, sobre todo, para reconocer su dependencia respecto a las condiciones sociales determinantes.

Esto no significa defender una forma de individualismo o de absolutización de la existencia individual. Adorno prevenía del peligro que encontraba en toda apelación a la interioridad subjetiva como recurso para acceder a la libertad. Cualquier intento de salir de la deformidad social mediante una acción realmente transformadora se vuelve inútil si no se toma conciencia de que también ella se encuentra sometida a un todo social injusto que bloquea cualquier intento de actuar y de vivir moralmente. No hay vida buena en medio de la falsa, pues no se puede pensar una idea de libertad individual dentro de una sociedad no emancipada. Esto significa que la conciencia de una vida realmente lograda depende de la eliminación de la parálisis social. Su filosofía representaba el esfuerzo por buscar espacios de emergencia para el individuo en medio de una totalidad social que lo desintegra, de ahí que sólo el fortalecimiento de la capacidad de pensar y de experimentar podría sobrepasar el estado social de parálisis. De manera irónica aseguraba que al individuo solo le quedaba "intentar vivir 
de tal modo que se puede creer haber sido un buen animal" (Adorno, 1970: 294). La auténtica emancipación sólo es posible a través del desenvolvimiento crítico de una razón capaz de captar su dimensión material y experimentar en sí misma la negatividad existente. Por eso, si en Lukács el antídoto para la cosificación era la remisión a la conciencia de clase, en Adorno lo es la experiencia. Solo a partir de la experiencia de la autonomización y de la abstracción real tal como es percibida por los individuos, es posible comprender la perspectiva adorniana.

Reconocer esta objetividad material que pesa sobre el sujeto en la sociedad del intercambio no significa caparla como algo definitivo. Por eso, propone el concepto de «totalidad negativa» como categoría crítica con la que transformar la lógica positiva hegeliana que Lukács quería revitalizar, en una lógica negativa del desmoronamiento. Al referirse a la totalidad, la Teoría Crítica quiere denunciar aquello que adopta la apariencia fetichista de inmediato o pseudonatural, cuando en realidad es constituido y mediado socialmente. Allí donde Marx señaló la prioridad de las condiciones materiales de las fuerzas productivas sobre la vida de los individuos, Adorno no ve una expresión de determinismo histórico. No se trata de una visión dogmática del mundo, sino de un diagnóstico sobre un estado falso que debe ser abolido. Contiene el momento de resistencia ante la totalidad del mundo social y, lo que es más importante, la demanda de su superación en un estado distinto de cosas tras la disolución de las condiciones dominantes que pesan sobre el sujeto:

\begin{abstract}
Éste es el giro decisivo de Marx. Que no dice simplemente, como cualquier socialista o anarquista primitivo que se opone a la sociedad burguesa: todo esto no es verdad. Sino que, además, dice: queremos, para cambiar este importante aparato, ponerlo en movimiento por sus propias fuerzas (...) En lugar de reprochar a la sociedad burguesa su pretensión de realizar la armonía, la toma muy en serio y se pregunta: ¿es la sociedad que enseñáis verdaderamente idéntica a su concepto? ¿Corresponde a vuestro mundo de intercambio libre y justo, como vosotros afirmáis, una sociedad libre y justa? (Adorno 1974: 261).
\end{abstract}

Por eso, la doctrina marxiana de la prioridad del ser sobre la conciencia es interpretada por Adorno como expresión de algo negativo, es decir, del predominio de la cosificación y de las relaciones de producción cosificadas que pesan sobre los individuos. Su énfasis en presentar las formas de las relaciones sociales como producto de la praxis humana permite pensar que existe en su teoría un resto de esperanza para el cambio social. Al negar que tienen validez más allá de algo que parece ser un fundamento pseudonatural, gana la posibilidad de que son históricamente devenidas y, por tanto, cambiable. En esta lectura dialéctica del concepto de totalidad social encuentra el sentido enfático del materialismo histórico así como su carácter utópico. Utopía no solo significa la presencia de un momento de protesta contra la lógica social dominante, sino también la posibilidad de experimentar la negatividad dentro de la positividad dominante. Por eso, en la reducción del mundo a una totalidad idéntica a sí misma permanece oculto un momento utópico: la voluntad de convertir lo distinto en igual. Por eso, no entiende su abolición como una restitución inmediata de la libertad sino, por el contrario, como la recaída en la antigua injusticia de la apropiación inmediata. La crítica al intercambio quiere la realización del ideal de 
cambio libre y justo, que no se ha cumplido. Este es el impulso utópico y transformador que pervive en toda filosofía materialista y al que dirige su pensamiento. Un impulso que surge de la propia situación real que quiere denunciar, una objetividad social como una totalidad antagónica que ha olvidado su génesis material y se presenta como «segunda naturaleza» ante la cual el individuo se siente impotente. El verdadero interés de una teoría social materialista se encuentra en la denuncia de las formas de vida dañadas y, también, en el deseo de dar lenguaje a lo oprimido en los procesos de racionalización. Por eso, la reflexión filosófica en el mundo administrado tiene lugar bajo la forma de oposición frente a cualquier opresión, pero también frente a todo intento de esconderlo o sublimarlo bajo fundamentos positivos. Tiene su punto de partida en la experiencia de humanidad y de emancipación frustrada, pero también en el deseo de evitar la recaída en la barbarie.

\section{BiBLIOGRAFíA}

Adorno, Th. W. (1962). Kierkegaard, Konstruktion des Ästhetischen, Gesammelte Schriften (en adelante, GS) 2. Suhrkamp: Frankfurt a.M.

Adorno, Th. W. (1970). Negative Dialektik, GS 6. Suhrkamp: Frankfurt a.M.

Adorno, Th. W. (1972). "Spätkapitalismus oder Industriegesellschaft?", GS 8. Suhrkamp: Frankfurt a.M.

Adorno, Th. W. (1973). "Die Idee der Naturgeschichte", GS 1. Suhrkamp: Frankfurt a.M.

Adorno, Th. W. (1974). Philosophische Terminologie. Suhrkamp: Frankfurt a. M.

Adorno, Th. W. (1984). "Musikpädagogische Musik. Brief an Ernst Krenek", GS 18. Suhrkamp: Frankfurt a.M.

Adorno, Th. W. (1995). Kants Kritik der reinen Vernunft. Suhrkamp: Frankfurt a.M.

Adorno, Th. W. (2003). "Graeculus II. Notizen zur Philosophie und Gesellschaft 19431969", Frankfurter Adorno Blätter VIII. Text+Kritik: München.

Escuela Cruz, C. (2018). "Moral y capital. Repensando el desafío ético de la Teoría Crítica", en: Escuela Cruz, C. y Álvarez, D. (coords.), Repensar la filosofía. La Laguna: Servicio de Publicaciones de la Universidad de La Laguna, pp. 69-89.

Festl, M. (2019). Scheitern an Kontingenz Politisches Denken in der Weimarer Republik. Frankfurt a.M.: Campus Verlag.

Horkheimer, M. (1985a). "Idee, Aktivität und Programm des Institut für Sozialforschung", Gesammelte Schriften 12. Fischer: Frankfurt a.M. 
Horkheimer, M. (1985b). "Rettung der Aufklärung. Diskussionen über eine geplannte Schrift zum Dialektik", Gesammelte Schriften 12. Fischer: Frankfurt a.M.

Horkheimer, M. (1987). "Metaphysische Verklärung der Revolution", Gesammelte Schriften 11. Fischer: Frankfurt a.M.

Horkheimer, M. y Adorno, Th. W. (1989). "Die verwaltete Welt oder: die Krisis des Individuums", Gesammelte Schriften 13. Fischer: Frankfurt a.M.

Jay, M. (2018). Fidelity to the Event? Lukács' History and Class Consciousness and the Russian Revolution, Studies in East European Thought.

Lukács, G. (1968). Geschichte und Klassenbewusstsein. Studien über marxistische Dialektik. Luchterhand: Neuwied/Berlin.

Marx, K. (1976). Zur Kritik der Hegelschen Rechtsphilosophie En: Marx, K. y Engels, F. Werke, 1. Berlin: Dietz.

Postone, M. (1993). Time, Labor and Social Domination. Cambridge: University Press.

Ramas San Miguel, C. (2018). Fetiche y mistificación capitalistas. La crítica a la economía política de Marx. Madrid: Siglo XXI.

Reichelt, H. (2013). Neue Marx-Lektüre. Zur Kritik sozialwissenschaftlicher Logik. Freiburg: Ça Ira.

Sacristán, M. (1983). Sobre Marx y el marxismo. Icaria: Barcelona.

Stöhr, R. et al. (2019). "Leiden beredt werden lassen". Theodor W. Adornos Reflexionen des beschädigten Lebens. Wiesbaden: Springer Fachmedien.

Westerman, R. (2019). Lukács's Phenomenology of Capitalism. Reification Revalued. Cham: Springer International Publishing.

Zamora, J.A. (2011). "Theodor W. Adorno: Crítica inmanente del capitalismo", en: Muñoz, J., ed. Melancolía y verdad. Invitación a la lectura de Th. W. Adorno. Madrid: Biblioteca Nueva.

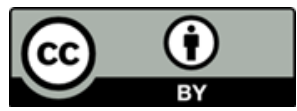

